\title{
Algunas Consideraciones Dialécticas y Hermeneutizantes sobre la Epistemología y la Importancia de la Tradición em el Pensamiento Turístico ${ }^{1}$
}

\section{Some Considerations Dialectics and Hermeneutics about Epistemology and the Importance of Tradition in the Thought Touristic}

\author{
Napoleon Conde Gaxiola ${ }^{2}$
}

\section{Resumen}

El tema es una reflexión sobre la epistemología y la tradición de los saberes turísticos y ociológicos desde la perspectiva de la hermenéutica dialéctica. Su objetivo consiste en aproximarnos a la configuración de un pensamiento latinoamericanista de estirpe analógica, orientada a esquivar las limitaciones objetivistas típicas del univocismo turisticológico y de las deficiencias subjetivistas propias de los estudios de la posmodernidad del tiempo libre. La metodología está basada en la perspectiva de la contradicción y el enfoque hermenéutico. El trabajo es una reflexión crítica sobre el estatuto específico del pensamiento turístico de la modernidad tardía, señalando de manera sucinta sus fortalezas y debilidades. Los principales hallazgos en la investigación son: la necesidad de un horizonte dialéctico, analógico e interpretacional del turismo, priorizando la dimensión epistémica y la relevancia de la tradición

Palabras clave: hermenêutica; dialéctica; analogia; tradición; epistemologia; antropologia; turismo justo y responsable

\begin{abstract}
This paper is about the epistemologic and tradition of tourism with a point of a view of dialectical hermeneutic. We will try to build a latin american thought with the purpose of avoid the positivism and the posmodernity. Our theory and methodology is the dialectical hermeneutic. Its subject is the study of epistemology and tradition in touristic thought. The methodology is dialectical hermeneutic. The most important results are the relevance of interpretation, analogy, hermeneutic, transformation and dialectical in these topics.
\end{abstract}

Keywords: hermeneutic; dialectical; analogy; tradition; epistemology; anthropology; tourism fair and responsible

\section{Resumo}

É um estudo sobre a hermenêutica do discurso turístico potencial epistemológico enfatizando o papel da ética, antropologia, ontologia, lógica e da analogia. Ele critica a posição cobertor de pensamento positivista e orientações turísticas factura típica dos relativistas pós-modernos.

\footnotetext{
${ }^{1}$ Trabalho apresentado no X Seminario Internacional de Turismo em Curitiba, Brasil.

2 Turismòlogo; Professor de la Escuela Superior de Turismo, Instituto Politècnico Nacional, Mèxico, D. F. Email: napoleon_conde@yahoo.com.mx
} 
Propõe postura interpretacional crítica e alternativas que visam estabelecer uma atitude prudente e medidas na reflexão de lazer, recreação e turismo.

Palavras-Chave: hermenêutica; dialética; analogia; tradição; epistemologia; antropologia; turismo justo e responsável

\section{Introducción}

En este trabajo me propongo reflexionar en torno a la epistemologicidad y a la tradición de un pensamiento turisticológico, desde la perspectiva de una óptica latinoamericanista y desde el campo de la Hermenéutica Dialéctica

Transformacional. Esta es la teoría y práctica de la interpretación basada en la metodología de la contradicción y del estudio de las analogías y las oposiciones en la esencia misma de los objetos (Conde: 1987, 2001, 2002a, 2002b 2004, 2005a,2005b, 2005c, 2006, 2007, 2008a, 2008b). Desde hace años hemos venido trabajando en esta dirección teórica y metodológica, tratando de aplicarla a la temática del tiempo libre y del turismo.

En ese sentido, nuestro artículo versa sobre la formación del saber turístico, la cuestión de la epistemología y el carácter multi, inter, y transdisciplinario de tal conocimiento.

\section{Desarrollo}

Desde hace un buen tiempo existe una marcada campaña orientada a la exacerbación y alteración de las posibilidades reales y concretas del turismo. Esto conduce a ubicarla como la industria número uno del mundo, la que posee mayor crecimiento económico, la que configura mayor fuerza de trabajo, la que más contribuye al PIB, la que genera mayor cultura y criterios de mundialización simbólica y otras temáticas similares. Esta postura neopositivista y postfuncional es a mi juicio de factura univocista y carece de dispositivos epistémicos en la configuración de su discurso, es decir, difícilmente podría ser visualizado dentro de un contexto científico, más bien responde a una estrategia administrativa de corte mercadotécnico que va desde los primeros propagandistas del turismo a finales del siglo XIX, hasta los creadores de la llamada sociología turística de los años treinta y cuarenta y de buena parte de los turisexpertos y turisespecialistas de talante empresarial y gubernamental en los últimos 50 años. En este contexto ha tenido mucho que ver la orientación mercantilista, instrumental y comercial de la Organización Mundial de Turismo y la creación de Secretarías, 
Ministerios, Oficinas, Departamentos y Direcciones Generales de Turismo a nivel municipal, estatal y nacional -que salvo raras excepciones- han diseñado en gran parte una diversidad de planes, programas y proyectos con el propósito de justificar y legitimar las políticas públicas de sus respectivos gobiernos. Igual función cumplen buena parte, por supuesto, no todos- de los departamentos de consultoría a nivel nacional e internacional que realizan "investigaciones por pedido", estableciendo conclusiones en función de los intereses económicos, políticos e ideológicos del cliente. Obviamente, en esos actores no existe ninguna inclinación epistémica y mucho menos ontológica y deóntica en su visualización del turismo; este mal por desgracia nos aleja de la cientificidad del turismo.

El propósito de este ensayo es generar argumentos basados en una idea epistémica del turismo en aras de convencer y persuadir a la comunidad turística de la vaguedad, imprecisión y ambigüedad de tales enunciados. Esa tendencia absolutista, partidaria de la excitación ideológica de la turisticidad, ha sido enormemente nociva y dañina en la historia de nuestra disciplina, que ha motivado a la risa, a la contracción y al sarcasmo ubicando el corpus de la turisespecialidad, como un dispositivo lejano del rigor conceptual, de la teoría de la argumentación y de la racionalidad analógica y dialéctica. Gran parte de esta inclinación nació en el campo de la administración, el derecho, la economía y la sociología del turismo y ha estado marcado por una fuerte tendencia neopositivista, clasicista y neoclásica, observable en términos administrativistas de Fabio Cárdenas (Cárdenas: 1986), juridicistas de Miguel Corchero (Corchero: 2008) y economicistas de Maria José Lorenzo, José Luis Calvo y Rubén Osuna (Lorenzo, Calvo, Osuna: 2003) y en el talante positivista, funcionalista y culturalista de las ciencias sociales.

En otra arista se ubica la concepción equivocista del turismo que cuestiona a diestra y siniestra la importancia del turismo, el ocio y el tiempo libre. En esta dimensión se ubican las posturas relativistas típicas de la posmodernidad, que se amparan en las propuestas genealogistas de Michel Foucault (Foucault: 1990), derridianas (Derrida: 1981), rizomáticas (Deleuze: 1989) y del llamado pensamiento débil (Vattimo: 1991), manifestada en ensayos del tipo de Daniel Boorstin (Boorstin: 1964), Jean Didier Urbain (Urbain: 1990); John Urry (Urry: 1990), Harkin (Harkin: 2005) y Pretes (Pretes: 1995). Si los univocistas pregonan a nivel extremista las bondades del turismo, los equivocistas se pasan a la otra arista, cuestionando de manera dóxica la especifidad de la turisticidad. Pretendo en este trabajo criticar la postura relativista del ocio y del tiempo libre por estar lejana a una propuesta 
analógica, diagramática, hermenéutica y dialéctica.

¿En qué consiste abordar la epistemologicidad del turismo desde una dimensión hermenéutica y dialéctica? ¿Cuáles son los criterios para acceder a una dimensión científica de los hechos turísticos?

a) El giro hermenéutico

De Aristóteles (Aristóteles: 1990) a Gadamer (Gadamer: 1990), de Pitágoras a Ricoeur (Ricoeur: 2000) y de Betti (Betti: 1995) a Beuchot (Beuchot: 2000), la hermenéutica ha tenido un largo camino. En su corpus categorial han emergido las teorías interpretacionales de mayor relevancia y trascendencia. Ha sido históricamente un saber especializado en la tipificación y caracterización de textos y si el turismo es un texto que debe ser develado y dilucidado, ella ocupa un espacio primordial. En la historia del pensamiento turístico han existido diversos enfoques hermenéuticos, destacando los trabajos de Patterson, Watson, Williams y Roggenbuck (Patterson, Watson, Williams y Roggenbuck: 1998), Patterson y Williams: (2002), Arcodia (2005), Kellee y Almeida (2008), James Clifford (Clifford: 1999) y el propio Clifford Geertz (Geertz: 1973). Desde América Latina han existido trabajos importantes, sobre todo desde Argentina (Otero: 2007), y en el caso de México hemos aplicado la hermenéutica desde que fundamos el primer posgrado de turismo en México, y uno de los primeros de América Latina, la Sección de Graduados de la Escuela Superior de Turismo hace un cuarto de siglo. En el largo camino de la turismología, turistología y/o ociología para convertirse de doxa en episteme y acceder al estatuto de ciencia, la hermenéutica ha ocupado y ocupará un sitio destacado, debido a la fortaleza de su dispositivo conceptual, a la tradición a la que pertenece y a la pertinencia de sus fuentes teóricas y metodológicas.

b) La postura analógica

La analogía surgió históricamente en la escuela pitagórica en la medida que buscaban la proporcionalidad de las cosas, la famosa frase: kat analogian, que significaba "según la proporción", les permitió ubicarse de manera prudencial entre los absolutismos y los relativismos de la época. Posteriormente, Aristóteles la ubicaría como dispositivo fronético, y los medievales le darían la envergadura de justo medio, orientado a evitar los extremos. En la modernidad escaseó su propuesta. Recientemente, el filósofo mexicano Mauricio Beuchot la rescató, universalizando sus tesis centrales. La analogía se puede entender como aquella teoría, cuerpo conceptual o actitud orientada a esquivar el univocismo y el equivocismo, el 
primero es el enfoque unidimensional, monosémico y esencialista; un ejemplo de ello es el positivismo de Sebastián de Grazia (De Grazia, 1966, 1997) y el funcionalismo turístico de Joffre Dumazedier (Dumazedier, 1962, 1966, 2002). El segundo es una postura típicamente posmoderna de corte relativista, proclive a la polisemia, a la interpretación infinita y a la ambigüedad, como se aprecia en los trabajos de Davidson y Spearrit (Davidson, Spearritt: 2005) y Marc Augé (Augé: 1986, 1997)

Entonces, ¿en qué consiste el horizonte analógico en el estudio del turismo? En primer lugar, se trata de un modelo de interpretación que evita sostener la existencia de un tipo único, exclusivo, impar, todopoderoso y omnipotente de saberes. Es lo que se conoce por univocismo. Lo unívoco fue identificado por Aristóteles en relación a la sinonimia, es decir, de los objetos que tienen en común el nombre o la definición de nombre. Guillermo de Occam lo identificará como el signo convencional que designa una sola cosa o un solo concepto. En esa medida, univocismo implica unidimensionalidad, monolitización, la exaltación parmenidiana de la "esfera", el ensalzamiento procliano del "uno", el realizar leibniziano de la "mónada", el mecanicismo cartesiano, el maquinismo la mettriano, la ontologización wolffiana, el estatismo hegeliano, y la dialéctica dogmática del marxismo absolutista, ya que todos ellos se encuentran articulados por la idea de homogeneidad, uniformidad, estandarización, perfección, completud y cabalidad.

Toda univocidad es una absolutización, un sellamiento reduccionista ante la otredad, ya que establece el acto de encastillarse y broquelarse ante la dialogicidad.

El univocismo es un monólogo narcisista negador del consenso y de la tolerancia; en el turismo lo vemos en las actitudes conductistas, en el positivismo, las tecnologías yoicas y las orientaciones religiosas fundamentalistas. Esta tendencia por lo general niega la heurística -en tanto parte del método vinculado a la invención-, estableciendo el primado de la matematicidad, la noción absolutista de ciencia, la hegemonía de la demostración, la literalidad, el cierre categorial y la superioridad de un cognitivismo de hechura objetivista y primordial. El propio Kurt Godel al establecer su famoso teorema de la incompletud señalaría que no puede formalizarse una prueba de consistencia para todo sistema axiomático en relación a los mismos axiomas, asestando así un duro golpe a las actitudes absolutistas (Godel: 1974).

La idea de que era posible axiomatizar a las matemáticas y establecer criterios de certeza 
absoluta se remonta al siglo VI antes de nuestra era, en la escuela de Crotona, donde enseñaba Pitágoras, pretendiendo numeralizar de manera arbitraria y abusiva todas las cosas, hechos y fenómenos del mundo externo. Esta línea unívoca tendrá su expresión más nítida en los inicios de la modernidad en Galileo Galilei al expresar que sólo es posible entender la naturaleza si tenemos acceso a la lengua matemática, excluyendo toda consideración cualitativa del estudio de la naturaleza, instituyendo el imperio de las relaciones numéricas, la mensurabilidad, la cantidad y la verificación. Todavía en el siglo XX Bertrand Russell manifestará su afán de encontrar un lenguaje ideal capaz de tipificar y caracterizar las cosas y eventos de la realidad. En el campo del turismo se ha presentado en las propuestas de un derecho positivo turístico inspirado en Hans Kelsen, el cual privilegia la coacción y el deber ser por encima de lo óntico y los derechos, tal como se observa en los trabajos de León (León: 2000).

En cambio, el horizonte analógico esquiva y evita esa absolutización con base en la iconicidad, la frónesis y la prudencia. En relación a los estudios de la cotidianidad y el tiempo libre, involucraría una reflexión mesurada y diagramática de los hechos, evitando las interpretaciones cerradas y enclaustradas. Ágnes Heller es un ejemplo del abordaje de tales cosas (Heller: 1994).

En el caso del equivocismo -que es la parte opuesta de la analogía- se observa una interpretación quebradiza, perecedera y endeble. Aristóteles lo vinculó a lo homónimo, designando a las cosas que tienen algo en común, en la medida que las definiciones aportadas por el nombre sean distintas y con abundante diferencia. Para Guillermo de Occam denota la pluralidad de las cosas. En la época contemporánea ha tenido vigencia en los posmodernismos de todo troquel, como es el caso del rizoma deleuziano y de la era del posdeber lipovetskiana. En el caso turistológico ha tenido una enorme incidencia en las propuestas que tienen su marco conceptual en los lineamientos relativistas de Feifer (Feifer: 1985) y Molina (Molina: 2006) en sus ideas de posturismo y en los trabajos de Baudrillard (Baudrillard: 1987, 1993).

En segundo lugar, la analogía supone una interpretación que prefiere el intelecto, ya que suministra las causas, las premisas y la comprensión, sirviéndose de la razón, para culminar con una conclusión, envío, síntesis y recolección; diferenciándose así del modelo univocista que privilegia el discurso cientista, objetivista y literal a través de la explicación cerrada para ahogarse en el océano de la linealidad. La propuesta analógica retoma la parte no unívoca de 
la explicación y el segmento no equívoco de la comprensión, para lograr o intentar alcanzar un modelo interpretante de corte explicativo y comprensivo. Es obvio que dicho modelo no denota una estigmatización de otras maneras del conocer ni trata de imponer de manera apriorística paradigmas categoriales ni establecer máximas deontológicas descalificando otras propuestas epistémicas.

En tercer lugar, adopta como criterio vertebral: la dialogicidad. El diálogo es la posibilidad de intercambiar puntos de vista de manera constante, febril y activa sin anclarse de forma fija e inmutable ante los saberes. Es la disposición a la conversación y a la modificabilidad creativa del habla escritural y verbal.

En cuarto lugar, se trata de adoptar una modalidad heurística. Ésta nos alecciona a cavilar de forma pertinente, en la medida que es una porción del método que nos traslada al hallazgo y a la revelación. Los esquemas unívocos y equívocos subestiman a la heurística basándose únicamente en la argumentación objetivizante y la narratividad total. La heurística es la aptitud para la creatividad, innovación e invención, implicando encontrar siempre una cosa nueva.

Para ser analógicos en el discurso turístico necesitamos una heurística. Nada más cómodo que la interpretación fonológica, catilinaria, amurallada, marcada por un cerco y un coto impenetrable, nada más simple que una interpretación infinita, inagotable, indeterminada, astillada y dividida. Muchos modelos univocistas alardean con el famoso paradigma de la complejidad. Otras orientaciones equivocistas presumen del aforismo, el apotegma y el tropo. Lo heurístico es lo analógico. Por eso decimos: ni complejidad absolutista ni alegoricidad relativista; sino analogicidad analógica en la puesta en escena de la cuestión turística.

En quinto lugar, abordamos el horizonte analógico desde varias perspectivas. Esto y más es la analogía, ya que se trata de no hacer de dicha perspectiva un ídolo, sino un icono; no otorgarle una coacción unívoca ni un disiparse de hechura equívoca. Lo icónico es el acompañante inseparable de lo analógico. Es la parte analógica del símbolo, el diagrama que capta la identidad y la diferencia. En esa medida es una analogicidad icónica.

En sexto lugar, la analogía supone una hermenéutica. El pensador mexicano Mauricio Beuchot ha desarrollado esta tipología de hermenéutica. Nosotros la hemos denominado hermenéutica analógica dialéctica transformacional. En ella la analogía ocupa un lugar central, ya que es conciliable, consensual y dialógica, es un modelo de interpretación que 
privilegia la heurística y la argumentación, la explicación y la comprensión, la condensación y el desplazamiento, la forma y el contenido, la diacronía y la sincronía, la razón y la emoción, lo concreto y lo abstracto, lo cuantitativo y lo cualitativo.

Por todo lo anterior pensamos que el turismo tiene la necesidad del recurso de la analogía para realizar su programa y sus fines.

\section{c) La dialéctica}

Es importante precisar que la dialéctica brilla por su ausencia en la inmensa mayoría de las ciencias sociales en general y de los saberes turísticos en particular, debido a cuestiones de carácter cognoscitivo y sociohistórico. La dialéctica es el estudio de las contradicciones en la esencia misma de los objetos, ya que consiste en estudiar la diversidad de los conflictos desde su génesis, evolución y teleologicidad en la naturaleza, la sociedad y el pensamiento. Al menos ese ha sido la idea que nos interesa de la misma, desde Heráclito a Hegel.

En el discurso del tiempo libre es necesaria cierta competencia dialéctica, es decir, la capacidad específica de un sujeto determinado para encontrar la especificidad de la contradicción en un contexto histórico concreto. La idea de dialéctica en Marx es sumamente peculiar y original, veamos lo que dice:

Mi método dialéctico no solo es fundamentalmente distinto del método de Hegel, sino que es, en todo y por todo, la antítesis de él. Para Hegel, el proceso del pensamiento, al que él convierte incluso, bajo el nombre de idea, en sujeto con vida propia, es el demiurgo de lo real, y esto la simple forma externa en que toma cuerpo. Para mí lo ideal no es, por el contrario, más que lo material traducido y traspuesto a la cabeza del hombre (Marx: 1976, XXIII).

Es decir, su reflexión es opuesta a las posturas idealistas y ahistóricas, asignándole un peso fundamental al papel del hombre en la transformación de la sociedad.

La mayor parte de los análisis sobre la cuestión del tiempo libre carece de dialecticidad, pues generalmente se ubican en una dimensión pasiva y estática de la realidad, sin entender el movimiento, el desarrollo y la evolución de las cosas. En ese sentido, en los discursos turisticológicos de la posmodernidad, la antidialecticidad se vislumbra en todos los rincones y asistimos por lo general a sesiones de corte congelado sin ninguna dinamicidad en el análisis del ocio, en perjuicio y daño de la comprensión del objeto de estudio.

Ahora bien, cuáles serían a nuestro juicio las características de una visión dialéctica del 
turismo.

- En un primer sitio se trata de privilegiar la metodología de la contradicción en oposición a las estrategias cognoscitivas orientadas a la conciliación, es decir, a aquellas propuestas de tipo funcionalista, como sería el caso de los trabajos sociológicos de talante spenceriano (Spencer: 1970), las orientaciones funcional estructuralistas de tipo parsonsiano (Parsons: 1975), y la sociología metafísica durkheimiana (Durkheim: 1980). Se trata de captar el rol de los opuestos al interior de los hechos turísticos. En cierta forma Adorno ha logrado entender esta peculiaridad en sus ya clásicos estudios sobre el ocio (Adorno: 2003)

- Una turistología deberá establecer una mirada de tipo interpretacional, superando las proposiciones ahistóricas típicas del funcionalismo. En el caso de Malinowski, desarrolló un procedimiento para penetrar en una comunidad, consistente en la llamada observación participante, a partir de la idea de que sólo sumergiéndose en una cultura, y siendo uno de los estudiados el observador puede descubrir y analizar las relaciones entre los elementos que componen dicha cultura. La observación participante es para Malinowski (Malinowski: 1948) la clave del análisis funcional, en tanto que ninguna función puede ser aprehendida fuera de esta estrategia de investigación. Esta indagación funcional es tan peculiar que lo conduce a entender la historia como un ente inerte y cerrado. Por supuesto que es importante la etnografía de la observación participante, pero si no se vincula a la dialecticidad, las investigaciones son vacías y débiles. En cambio, para el turismo la dialéctica deberá concebirse como un saber histórico centrado en la diacronicidad, esto permitirá entender los hechos de la temporalidad sobrante de forma objetiva y paradigmática. De hecho, Marcuse (Marcuse: 1968) lo visualizó de manera cabal en su tipificación de la sociedad contemporánea

- La antigua discusión orientada a dividir las ciencias en dos segmentos: ciencias de la naturaleza y ciencias del espíritu, impulsadas por el historicismo de Dilthey (Dilthey: 1965), por el neokantismo de Windelband y alimentada de manera acrítica por Geertz (Geertz: 1973) condujo a pensar que el proyecto hermenéutico de la antropología y sociología en general y el turismo en particular se basaría única y exclusivamente en las ciencias humanas, en aras de huir del paradigma positivista. Esta tendencia caería de una u otra forma en posiciones equivocistas, caracterizadas por privilegiar de manera ambigua lo cualitativo por encima de lo cuantitativo y a suponer que únicamente los procedimientos comprensivos serían suficientes en el análisis turístico en detrimento de los enfoques explicativos. Este tipo 
de estudio es observable en los trabajos de Clifford Geertz.

- A nuestro juicio un enfoque dialéctico del turismo supera el ámbito de lo cuantitativo, propio del positivismo, el funcionalismo, el conductismo y el cognitivismo del pensamiento turístico, rebasando a su vez las ópticas cualitativistas típicas de la sociología hermenéutica geertziana, ya que un enfoque dialéctico articula lo deductivo y lo inductivo, lo teórico y lo práctico, lo fenoménico y lo esencial, lo objetivo y lo subjetivo, lo paradigmático y lo sintagmático y la identidad y la diferencia. Es importante señalar que la idea de dialéctica que aquí tenemos adopta sus tesis centrales del pensamiento marxista, en ese sentido el filósofo italiano Incola Abbagnano dice:

Por otra parte, la noción de dialéctica fue utilizada por Marx, Engels y sus seguidores, en el mismo sentido establecido por Hegel, pero despojándolo del significado idealístico que mantenía en el sistema hegeliano. Lo que reprocha Marx al concepto hegeliano es que la dialéctica para Hegel es conciencia y permanece en la conciencia, nunca alcanza el objeto, la realidad, la naturaleza, si no es con el pensamiento y como pensamiento. Según Marx toda la filosofía hegeliana vive en la abstracción y, por ende, no describe la realidad y la historia si no es como imagen abstracta, que en último análisis se coloca como verdad suprema en el $<<$ Espíritu absoluto $>>$. Por consiguiente Marx propugna la exigencia de que la dialéctica pase de la abstracción a la realidad, del mundo cerrado de la $<<$ conciencia $>>$ al mundo $<<$ abierto $>>$ de la naturaleza y de la historia (Abbagnano: 1971, 22).

Esa idea marxista de dialéctica supera de manera arrolladora las propuestas quietistas y contemplativas no sólo de Hegel, sino de buena parte de las dialécticas griegas, romanas y medievales. Para Marx se trata de pasar de la teoría a la práctica, de la abstracción a la concreción y de la pasividad a la actividad práxica y transformadora.

- El análisis dialéctico del turismo prioriza una orientación holística en su interpretación de la recopilación de datos, debido a que establece un reconocimiento económico, político, social e ideológico de los hechos estudiados. En nuestro trabajo de investigación tratamos de demostrar que los estudios no dialécticos abordan procedimientos fragmentarios, debido a la incapacidad de los investigadores para aproximarse a posiciones totalizantes. La totalidad dialéctica y analógica implica una competencia semántica, sintáctica y pragmática para establecer un enlace relacional entre la parte y el todo, lo particular y lo general, la necesidad y la casualidad, la determinación y la indeterminación. En ese sentido tiene razón el filósofo Karel Kosík cuando dice: 
La actitud que el hombre adopta primaria e inmediatamente hacia la realidad no es la de un sujeto abstracto cognoscente, o la de una mente pensante que enfoca la realidad de un modo especulativo, sino la de un ser que actúa objetiva y prácticamente, la de un individuo histórico que despliega su actividad práctica con respecto a la naturaleza y los hombres y persigue la realización de sus fines e intereses dentro de un conjunto determinado de relaciones sociales. Así pues, la realidad no se presenta originariamente al hombre en forma de objeto de intuición, de análisis y comprensión teórica -cuyo polo complementario y opuesto sea precisamente el sujeto abstracto cognoscente que existe fuera del mundo y aislado de él-; se presenta como el campo en que se ejerce su actividad práctico-sensible y sobre cuya base surge la intuición práctica inmediata de la realidad. En la relación práctico-utilitaria con las cosas, en la cual la realidad se manifiesta como un mundo de medios, el individuo <<en situación $>>$ se crea sus propias representaciones de las cosas y elabora todo un sistema correlativo de conceptos con el que capta y fija el aspecto fenoménico de la realidad. (Kosik: 1967, 25-26)

Para el filósofo checo lo importante es un estudio filosófico que sitúe al hombre en el centro de su problemática, la cual se da en la medida en que entiende la totalidad y se aleja de interpretaciones reduccionistas y subjetivistas. Eso es el ingreso a la dialéctica, en tanto método crítico de transformación de la realidad. En el caso del turismo esto conlleva a ubicar al ser humano a un alto nivel óntico, antropológico y deóntico, elementos poco observables en nuestra disciplina.

- Esta propuesta conduce a adoptar un criterio interpretacional de corte genético, historizante, teleológico y crítico, adoptando un enfoque integral, sistémico y relacional, lo cual implica entre otras cosas articular la explicación y la comprensión, es decir, no se contenta de manera exclusiva con el uso de la intuición y la experiencia en el prototipo comprensivista, ya que cree necesario la adopción de los modelos explicacionales. La dialéctica tiene que ver con la gran revolución epistémica generada por Marx a mediados del siglo XIX, ya que veía la necesidad de partir de la razón política, práctica y material, pues no se puede asegurar la reproducción material de la vida humana si no aseguramos la reproducción de la naturaleza material. En ese sentido, la reproducción material de la vida humana es el criterio primordial de toda existencia en sociedad, y de manera específica en el caso turístico.

Por otro lado, requiere de un enfoque histórico del objeto de estudio, entendiendo por historia una perspectiva científica del pasado distante y un análisis radical del presente, poniendo en tela de juicio las concepciones univocistas de la historicidad, típicas de las orientaciones postpositivistas (Walachow: 2001) y las concepciones relativistas del corte de Roger Chartier 
(Chartier: 2005), Arthur Danto (Danto: 1996) y otros. Los primeros desvinculan la historia de la ética y la justicia, adoptando un criterio instrumental, normativo y coactivo; y los últimos de enclaustran en una concepción narrativista, alegórica y poética de la misma. Muy similar a algunos enfoques económico-administrativistas (Cárdenas: 1986) y juridicistas (Corchero: 2008) del turismo y en las posturas ociológicas posmodernas al estilo de Urbain (Urbain, 1990). Muy por el contrario, Frederic Munné nos acerca a una visión crítica, analógica y compleja del ser humano (Munné: 1995, 2004, 2007)

d) La transformacionalidad

El rol de la transformacionalidad es vital en toda reflexión sobre el tiempo libre, ya que evita los enfoques contemplativos y tiende a la facticidad de las cosas. Lo transformacional representa praxis. Ésta no es un ejercicio opuesto a la teoría, sino determinación e insistencia del hombre para transformar críticamente la realidad objetiva. En esa vía, ha de tratar del hombre y de su puesto específico en el universo, es decir, de la totalidad del mundo, que se revela en su historicidad, y el hombre existente en la totalidad del mundo, que se manifiesta en la historia del hombre, y ese hombre concreto en la totalidad del mundo. En ese sentido podemos decir que los saberes turísticos y ociológicos son antropológicos -por el papel primordial que juega el hombre en ese contexto- y de no ser así, no lo son, es decir, si no contemplan una teoría del ser humano se alejan del contenido filosófico de nuestra disciplina; en ese sentido, la transformacionalidad se orienta hacia la destrucción del horizonte de la falsa realidad. Aquí la realidad turística no es un conjunto desarticulado de hechos, fenómenos, nexos y procesos, es decir, de oferta turística, demanda turística, comunidad receptora, instituciones constructoras de política turística, empresas y fuerza de trabajo, sino su arqueologización, estructura, función, creación y teleologización, es decir, existe un vínculo indisoluble entre hechos y totalidad. Buena parte de la historia del turismo, desde Thomas Cook hasta los planteamientos posmodernistas, y desde Von Wiese (Von Wiese: 1930) hasta los univocismos recientes no han comprendido esta situación, abordando como fuente de análisis, temáticas que en su mayor parte ha caído en la pseudo-objetividad, ya que no han entendido lo que es la totalidad concreta. Esa tarea de una "hermenéutica profunda del turismo" no puede por ningún motivo postergarse ni retrasarse, ya que la praxis es algo mencionado constantemente, pero escasas veces reflexionado. Entender la praxis de las concepciones del mundo, refuncionalizar la praxis, reconstituir la praxis turística, así como sus fundamentos; comprender la praxis, a su vez, en el ámbito de la razón práxica, es decir, ir 
más allá de la práctica vulgar en aras de influir en el devenir, interpretar las totalidades e incidir en la historia y el devenir a través de una conciencia dinámica. Ésta podría ser una de las facetas de una dimensión transformacional del quehacer turístico, al menos desde América Latina, donde se hace necesario un enfoque crítico.

e) La tradición

Pertenecer a una tradición es sin duda alguna un acontecimiento de singular importancia. A partir de ello se puede desentrañar nuestra ideología, concepción del mundo y pensamiento, si pretendemos que la hermenéutica dialéctica sea una postura nuestraamericana, tendrá que estar vinculada a la historia de los países de América Latina y del Caribe en general y el quehacer turístico y del tiempo libre en particular, no sólo en términos epistémicos, sino a nivel sociohistórico. Para interpretar tal realidad, tendremos que partir de nuestra génesis, explorando nuestros bulbos y cepas ónticas, históricas, éticas y cognoscitivas, lo cual nos llevará a una idea de lo turístico, desde una perspectiva crítica y nueva.

Obviamente, aquí no se clausura el contenido epistémico y la tradición de un pensamiento turístico de nuevo tipo. Para concretar tal idea se hace necesario elevar tales saberes al estatuto de ciencia. Nuestro concepto de ciencia es hermenéutico, pues conlleva la existencia de un corpus categorial enlazado, sistematizado y relacionado, lejano de los criterios verificacionistas del llamado Círculo de Viena. Este conocimiento turístico deberá contener elementos semánticos, sintácticos, pragmáticos, problematizantes, hipotéticos, téticos, demostrables, basados en la quididad y el busilis, en la abducción, la eticidad, lo deóntico, lo óntico y la antropología.

En ese sentido, ¿a qué tradición pertenece nuestra propuesta?

Sin duda alguna, se adscribe a una postura contestataria, lejana de actitudes cortesanas. La posmodernidad ha declarado la muerte a la ontología, el cambio social y el conflicto societal. Sin embargo, podemos decir que en la historia de las ideas siempre se ha dado esta paradoja, cada crimen al logos implica un espacio central de la indagación emancipatoria, o sea, un debate entre las posturas vitales y liberadoras y las tendencias necrófilas y nihilistas. En el propio pensamiento turístico ha emergido un movimiento que se resiste a la posmodernidad y procura volver a la vitalidad de la contradicción y de la propuesta del cambio social. Se observa en la lucha por un turismo justo y responsable en las comunidades pesqueras, agrícolas, silvícolas y ganaderas, en el manejo racional y creativo del tiempo libre de las 
comunidades indígenas y campesinas, en el conocimiento del agroturismo y en la autogestión de proyectos turísticos en espacios locales y municipales. Sin embargo, es menester reconocer que los tiempos actuales son de "esbeltez" epistémica y transformadora, pues existen infinidad de individuos llenos de actitudes colaboracionistas y complicidad hacia el príncipe en turno. Son tiempos del sujeto light que cambia de ideología a cada instante: fenomenólogo ayer, conductista hoy, sistémico mañana y posmoderno pasado mañana o también marxista ayer, socialdemócrata hoy, republicano mañana y comunitarista pasado mañana. En esa vía, el pensamiento turístico puede perder su tejido contestario de reflexión y los dispositivos teóricos y fácticos derretirse, ya que en muchos casos la reflexión económico-política se diluye en aras del giro lingüístico y del pensamiento débil.

Sin embargo, son muchos los retos que deberá enfrentar un pensamiento turístico de nuevo tipo. Un desafío que nos atañe a quienes hemos visto durante décadas la fragilidad del hecho turístico, en donde se ha presentado una serie de cambios económicos, políticos, sociales, culturales y simbólicos en comunidades ejidales, indígenas, pesqueras, artesanales por combinados, cruzados de turisticidad (monopolios hoteleros, gastronómicos, aéreos y de espectáculos), trayendo en consecuencia la reducción de sus creencias, fiestas, ritos, peregrinaciones y mitos, reduciendo su concepción del mundo y tejidos culturales, como ha sucedido en cierta forma en el Caribe mexicano. Igual situación ha acontecido en otros espacios de nuestraamérica. Esto nos sugiere una serie de interrogantes que deberán formularse con seriedad al inicio del nuevo milenio: ¿qué tan importante ha sido el turismo en términos de vitalidad y bienestar económico, social, comunal, cultural, simbólico y moral en nuestras comunidades? ¿Hasta qué punto es posible transformar en beneficios para la sociedad la enorme ganancia turística de los grupos monopólicos? ¿De qué manera se puede aprovechar la globalización y la mundialización del sector turismo el crecimiento de nuestros pueblos? ¿De qué forma se puede incidir en la configuración de políticas públicas del ocio, la cultura, el tiempo libre y el turismo de manera participativa, creativa y democrática? ¿Qué nexos existen entre la democracia y el turismo? Las experiencias inmediatas de los hechos turísticos en México y de otros países de América Latina nos llevan a formularnos un conjunto de sospechas que al epistemologizarse posibilitarán que los saberes del tiempo libre naveguen en mares más seguros y certeros. Los nuevos tiempos exigen posiciones de talante deóntico que los expertos del ocio deberán sin duda alguna asumir.

En ese horizonte se hace necesaria una ética del turismo, una ontología del tiempo libre, y una 
antropología del ocio. La filosofía de la filosofía del turismo es una tarea aún por construir. Eso implica reflexionar sobre la idea de sociedad, cultura, cambio social, uso creativo del tiempo libre, fetichización, cosificación, alienación y enajenación en su relación con el turismo en la coyuntura presente. En este contexto se fortalecerá nuestra herencia tradicional y la epistemología de nuestra disciplina.

Aquí la hermenéutica dialéctica podría aportar algunos elementos que quizá podría ayudar a superar la scilla del absolutismo y la caribdis del relativismo, tan en boga actualmente en el discurso turístico.

\section{Conclusiones}

Es imprescindible diseñar los componentes de un enfoque epistémico del turismo, dado que nos interesa acercarnos a un turismo responsable y justo, esto es a nuestro juicio de enorme valor en la coyuntura actual de nuestra disciplina. La posibilidad de construir una situación ideal de diálogo entre profesores, investigadores, empresarios, trabajadores, funcionarios y comunidad receptora, implicará beneficios para a sociedad en su conjunto. Si tenemos un conocimiento científico del turismo podremos configurar propuestas relevantes y trascendentales, en beneficio de la población más afectada por las políticas turísticas injustas, aplicadas a nivel local, municipal, estatal y nacional. Es imperioso sostener el complejo balance de la mesura, sin anclarse en la univocidad absolutista del positivismo turístico ni caer en la equivocidad relativista de la anfibología del llamado tiempo libre. En ese camino, nuestra propuesta podría aportar elementos para superar el estancamiento en el que se encuentran los saberes turísticos, aportando algunas herramientas para estudiar de manera más integral y holística nuestro objeto de estudio. Una veta hermenéutica, dialéctica y transformacional estaría en condiciones objetivas y subjetivas de sugerir criterios para avanzar en esa ruta. No olvidemos que un modelo epistémico a veces enseña más por el paradigma de ser humano que construye que por el tejido discursivo que presenta, aunque sin duda alguna éste es determinante. La parálisis y la crisis de la epistemología del turismo es una muestra de ello. En ese camino, tenemos la esperanza de que nuestra oferta cognoscitiva proporcione senderos y señales. 


\section{Referencias}

ABBAGNANO, Incola. 1971. La evolución de la dialéctica. Martínez Roca, Barcelona.

ADORNO, Theodor. 2003. Consignas. Amorrortu Editores, Buenos Aires-Madrid.

ARCODIA, Charles. 2005. Cauthe Conference Exploring the use of hermeneutics as a research methodology within tourism contexts. School of Tourism \& Leisure management, The University of Queensland, Australia.

ARISTÓTELES. 1995. Metafísica. Porrúa, México.

AUGÉ, Marc. 1986. El viajero subterráneo. Un etnólogo en el metro. Gedisa, Madrid. 1997. El viaje imposible. El turismo y sus imágenes. Gedisa, Madrid.

BAUDRILLARD, Jean. 1987. América. Ed. Anagrama, Barcelona. 1993. Cultura y simulacro. Kairós, Madrid.

BETTI, Emilio. 1995. Teoria generale della interpretazione. TIP, Roma.

BEUCHOT, Mauricio. 2000. Tratado de hermenéutica analógica. UNAM, México.

BOORSTIN, D. 1964. The image guide to pseudo-events in América. Atheneum, New York.

CÁRDENAS, Fabio. 1986. Producto turístico. Trillas, México.

CHARTIER, Roger. 2005. El presente del pasado. UIA, México.

CLIFFORD, James. 1999. Itinerarios transculturales. Gedisa, Barcelona.

CONDE, Napoleón. 1987. Apuntes sobre hermenéutica y turismo. Sección de Graduados, Escuela Superior de Turismo, Instituto Politécnico Nacional, México DF.

México.

2001. La filosofía de los derechos humanos de Mauricio Beuchot. Primero Editores,

2002a. Dos aplicaciones de la hermenéutica analógica: el urbanismo y el turismo. Torres Asociados, México.

. 2002b. Hermenéutica analogical, definición y aplicaciones. Primero Editores, México.

2004. Ensayos sobre hermenéutica analógica. Número especial de Analogía, México.

2005a. Hermenéutica analógica, aspectos filosóficos actuales. Número especial de Analogía, México.

2005b. La hermenéutica analógica y la cuestión cultural en México. Ducere, México.

2005c. Hermenéutica analógica y formación docente. Torres Asociados, México.

2006. Breve historia de la hermenéutica analógica. Torres Asociados, México.

2007. El contexto de la hermenéutica analógica. Torres Asociados, México.

. 2008a. La hermenéutica dialéctica transformacional y la cuestión jurídica. IPN, México.

2008b. La hermenéutica dialéctica transformacional, el turismo, el derecho y la cuestión social. IPN, México.

CORCHERO, Miguel. 2008. Derecho del turismo. Iustel Publicaciones, Madrid.

DANTO, Arthur. 1996. Historia y narratividad. Paidós, Madrid.

DAVIDSON, Jim; SPEARRITT, Peter. 2005. Holiday Business: Tourism in Australia Since 1870. Melbourne University Press, Australia. 
DE GRAZIA, Sebastián. 1966. Tiempo, trabajo y ócio. Tecnos, Madrid.

1997. A country with no name. Random House, New York.

DELEUZE, Gilles. 1989. Lógica del sentido. Paidós, Barcelona.

DERRIDA, Jacques. 1981. La gramatologia. Siglo XXI editores, México, DF.

DILTHEY, Wilhelm. 1965. Introducción a las ciencias del espíritu. FCE, México.

DUMAZEDIER, Joffre. 1962. Vers une civilisation du loisir? Paris, Seuil.

1966. Loisir et culture. In: DUMAZEDIER, Joffre; RIPERT, Aline Ripert; avec la collaboration d'Yvonne Bernard et de Nicole Samuel. -- Paris : Edic. du Seuil. sociales, Lyon.

2002. Penser l'autoformation société d'aujourd'hui et pratiques d'autoformation. Chroniques

DURKHEIN, Emilio. 1980. Las formas elementales de la vida religiosa. Schapire, Buenos Aires.

FEIFER, M. 1985. Going Places. MacMillan, London.

FOUCAULT, Michel. 1990. Microfísica del poder. La Piqueta, Madrid.

GADAMER, Hans Georg. 1990. Verdad y método. Sígueme, Salamanca, España.

GEERTZ, Clifford. 1973. La interpretación de las culturas. Gedisa, Barcelona.

GODEL, Kurt. 1974. Collected works. Oxford University Press: New York. Editor-in-chief: Solomon Feferman.

HARKIN, Michael Eugene. 2003. Staged Encounters: Postmodern Tourism and Aboriginal People. Ethnohistory - Volume 50, Number 3, Summer 2003.

HELLER, Ágnes. 1994. Sociología de la vida cotidiana. (traducción de J.F. Ivars y Eric Pérez Nadal) 4a ed, Ediciones Península. Barcelona.

KELLEE, Caton; ALMEIDA, Carla Santos. 2008. Closing the hermeneutic circle? Photographic encounters with the other Annals of Tourism Research : a SocialSciences Journal, Marzo de 2008.

KOSIK, Karel. 1967. Dialéctica de lo concreto. Grijalbo, México.

LEÓN, D. G. 2000. Introducción al derecho turístico. IPN, México.

LORENZO, Maria José; CALVO, José Luis; OSUNA, Rubén. 2003. Economía del turismo. Centro de Estudios Ramón Areces. Madrid.

MALINOWSKI, Bronislaw. 1948. Teoría científica de la cultura. Siglo XX, Buenos Aires.

MARCUSE, Herbert. 1968. El hombre unidimensional. Joaquín Mortiz, México.

MARX, Carlos. 1976. El capital. Tomo I, FCE, México.

MOLINA, Sergio. 2006. El posturismo: turismo y posmodernidad. Trillas, México.

MUNNÉ, Frederic. 1995. Psicosociología del tiempo libre. Trillas, México.

. 2004. El retorno de la complejidad y la nueva imagen del ser humano: Hacia una psicología compleja. Revista Interamericana de Psicología, 38 (1), 21-29, Madrid.

2007. ¿La explicación del comportamiento humano debe ser lo más simple posible o lo más compleja posible? Encuentros en Psicología Social (Universidad de Málaga), 2007, 4, 3-10

MUNT, I. 1994. The 'Other' Potmodern Tourism Culture, Travel and the New Middle Classes. Theory, Culture \& Society, 11, 101-123.

OTERO, Adriana. 2007. Una vision de la creación de capacidades en turismo desde la perspectiva de 
la hermenéutica filosófica barroc. en Arriarán Samuel (coordinador) La hermenéutica en América LatinA. Itaca, México.

PARSONS, Talcot. 1975. El sistema social. Revista Occidente, Madrid.

PATTERSON, Michael E.; WILLIAMS, Daniel R. 2002. Collecting and analyzing qualitative data: Hermeneutic principles, methods and case examples. Advances in Tourism Applications Series. Volume 9. Champaign, IL: Sagamore Publishing, Inc.

; WATSON, Alan E.; WILLIAMS, Daniel R.; ROGGENBUCK, Joseph R. 1998. An hermeneutic approach to studying the nature of wilderness experiences. Journal of Leisure Research, Vol. 30.

PRETES, M. 1995. Postmodern Tourism: The Santa Claus Industry. Annals of Tourism Research, 22(1), 1-15.

RICOEUR, Paul. 2000. Sí mismo como otro. Siglo XXI editores, México.

SPENCER, Herbert. 1970. Principios de sociologia. Revista de Occidente, Madrid.

URBAIN, J. 1990. El idiota que viaja. Endymión, Madrid.

URRY, J. 1990. The tourist gaze: leisure and travel in contemporary societies. Sage, London.

VATTIMO, Giani. 1991. Éticas de la interpretación. Paidós, Madrid.

VON WIESE, Leopold. 1930. Fremdenverken alz zwischenmens chliche arch frendenverkehr. Frankfurt.

WALACHOW, W. 2001. The positivism legal inclusive. Oxford Clarendom Press.

\section{Recebido em: 28/07/2008}

Aprovado em: 22/09/2008 